\title{
Defensive Behavior in Stejneger's Snail Sucker, Sibon longifrenis (Serpentes: Dipsadidae)
}

\author{
Juan G. Abarcaㄹ, Diego A. Gómez Hoyos², Rocío Seisdedos-de-Vergara², and Alejandro Quesada Murillo \\ ${ }^{1}$ Laboratory of Natural Resources and Wildlife, National University, Heredia, Costa Rica (barcazajuan@gmail.com) \\ ${ }^{2}$ Procat International (biodiego88@gmail.com; rociro3@gmail.com) \\ ${ }^{3}$ School of Biology, University of Costa Rica (alejandro.qm10@gmail.com)
}

S lug- and snail-eating snakes in the genera Sibon, Dipsas, Sibynomorphus, Plesiodipsas, and Tropidodipsas are common species in Neotropical rainforests (Harvey and Embert 2008). They feed mainly on soft-bodied animals and frog eggs (Lewis et al. 2013). In general, dipsadine snakes are docile when handled and never attempt to bite as a defense. Although they generally do not open their mouths or bite, many extend their heads and some assume defensive postures similar to those of vipers (Rojas and Escobar 2010). Another typical behavior is to coil their bodies, which protects the head against the attack of a predator (Lewis and Lewis 2010). Many variations of this behavior have been described, and although the same species may exhibit several types of defensive behaviors, different species may also have similar behaviors (Cadle and Myers 2003).

Stejneger's Snail Sucker (Sibon longifrenis) inhabits Costa Rica, Honduras, Nicaragua, and Panama. It is relatively common along the Caribbean slope of Costa Rica (Solórzano 2001). These are medium-sized, nocturnally active snakes whose diets are comprised mainly of frog eggs, oligochaetes, and mollusks (Ray et al. 2012). Patches of white, green, and brown in a disruptive moss- or lichen-like pattern blend well in its arboreal tropical habitat (Solórzano 2001, 2004). Despite being a commonly encountered species, no defensive behaviors have been reported. Cadle and Myers (2003), who reviewed defensive strategies in dipsadines, failed to mention S. longifrenis. Herein, we report for the first time a defensive behavior of $S$. longifrenis.

At 1800 h on 17 November 2018 in a garden area within a forested patch in the Mistico Arenal Hanging Bridges Park, located in La Fortuna of San Carlos, Alajuela Province, Costa Rica $\left(10.4900^{\circ} \mathrm{N}, 84.7545^{\circ} \mathrm{W}\right.$; WGS 84; elev. $\left.626 \mathrm{~m}\right)$, we observed an adult Sibon longifrenis on an unidentified plant at a height of $1.5 \mathrm{~m}$. When we began to take photographs of the snake on a branch, it coiled its body into a suspended, symmetrically flat spiral with its head hidden in the center (Fig. 1). It maintained this posture for more than 6 min of observation. At no time did the snake attempt to bite or escape. This behav-

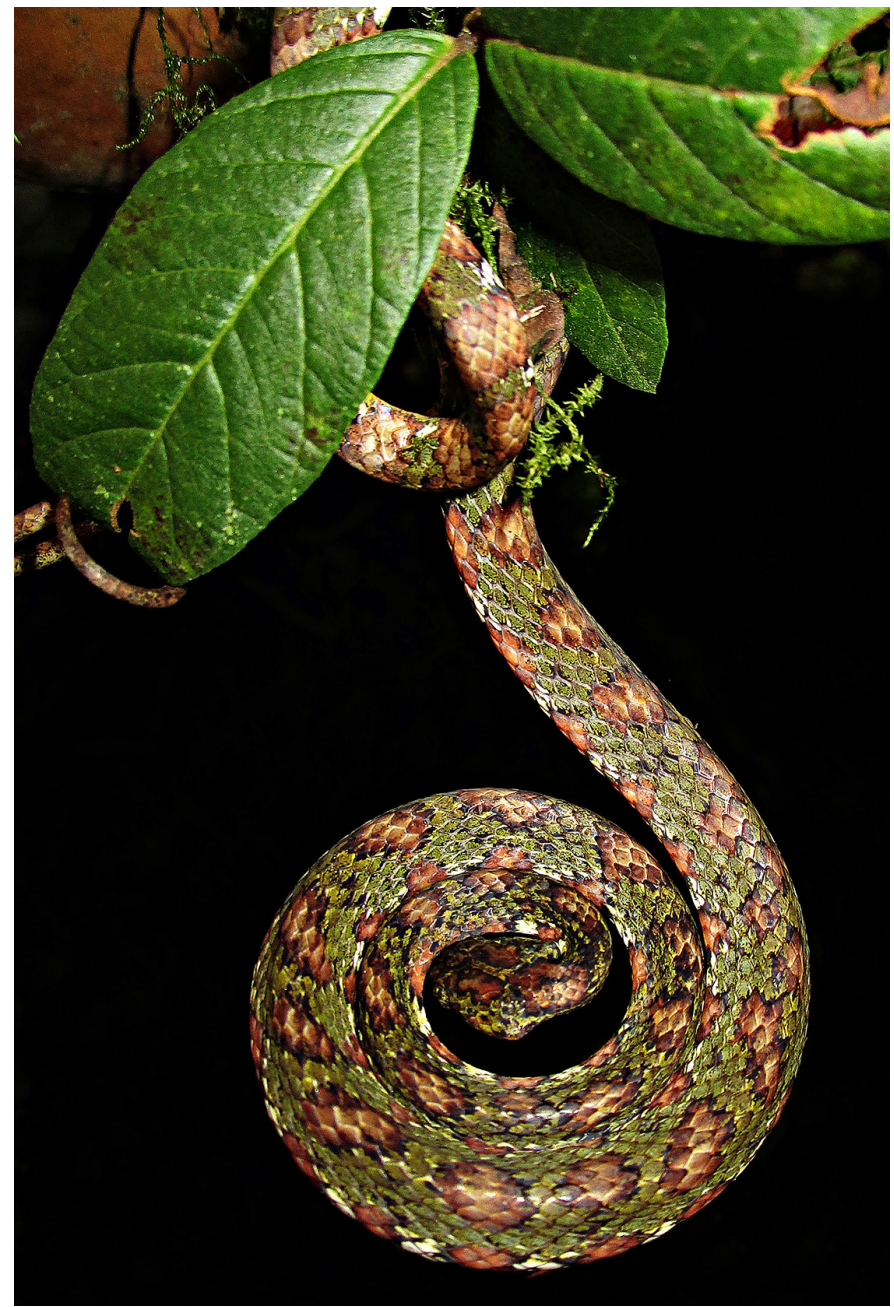

Fig. 1. Defensive behavior assumed by an adult Stejneger's Snail Sucker (Sibon longifrenis). Photograph by Juan G. Abarca.

ior was repeated several times during the photo session. When the snake was subsequently released, it coiled itself in the same way on a palm leaf and maintained that posture until we left.

The coiling process was similar to that described for Sibon argus and Dipsas nicholsi (Cadle and Myers 2003), but 
in S. longifrenis the product was a flat spiral instead of a spring as in the other two species. Silveira et al. (2018) described a more similar posture in $D$. albifrons, which seemed to flatten its body before assuming a tightly coiled posture. One of the most common defensive behaviors in snakes is to coil into a ball, pyramid, or spring while hiding the head. Such behaviors usually occur when the snake is disturbed or feels threatened by a predator (Cadle and Myers 2003). Sibon longifrenis also might be mimicking the fiddlehead of a fern or the coils of an Eyelash Viper (Bothriechis schlegelii), with which it shares a color pattern (Solórzano 2001). Mimicking the color pattern and movement of venomous snakes is also a common behavior (Rojas and Escobar 2010). Defense mechanisms of snakes are very diverse, and for species that lack venom or large size, simulating an inanimate object or a dangerous model apparently serves to confuse a predator.

\section{Acknowledgements}

We thank the staff of Mistico Arenal Hanging Bridges Park for allowing us access to the property.

\section{Literature Cited}

Cadle, J.E. and C.W. Myers. 2003. Systematics of snakes referred to Dipsas variegata in Panama and western South America, with revalidation of two species and notes on defensive behaviors in the Dipsadini (Colubridae). American Museum Novitates 3409: 1-47.

Lewis, T.R. and O.J.J. Lewis. 2010. Defensive behavior in Dipsas articulata (Cope 1868). Herpetozoa 23: 79-81.

Harvey, M.B. and D. Embert. 2008. Review of Bolivian Dipsas (Serpentes: Colubridae), with comments on other South American species. Herpetological Monographs 22: 54-105

Lewis, T.R., R. Griffin, P.B.C. Grant, A. Figueroa, J.M. Ray, K.E. Graham, and G. David. 2013. Morphology and ecology of Sibon snakes (Squamata: Dipsadidae) from two forests in Central America. Phyllomedusa 12: 47-55.

Ray, J.M., C.E. Montgomery, H.K. Mahon, A.H. Savitzky, and K.R. Lips. 2012. Goo-Eaters: Diets of the Neotropical Snakes Dipsas and Sibon in central Panama. Copeia 2012: 197-202.

Rojas, J.A. and S. Escobar Lasso. 2010. Defensive behavior of Dipsas sanctijoannis (Serpentes: Dipsadidae). Phyllomedusa 9: 147-150.

Silveira, A.L., L. Ribeiro, T.T. Dornas and T.N. Fernández. 2018. New records of Dipsas albifrons (Serpentes, Dipsadidae) in the Atlantic Forest of Minas Gerais, Brazil, with morphological data. Herpetology Notes 11: 809-815.

Solórzano, A. 2004. Serpientes de Costa Rica: Distribución, Taxonomía e Historia Natural. Editorial INBio, Santo Domingo de Heredia, Costa Rica.

Solórzano, A. 2001. A new species of snake of the genus Sibon (Serpentes: Colubridae) of the Caribbean slope of Costa Rica. Revista de Biologia Tropical 49: 1111-1120. 